Comparing Motivations and Intentions of Potential Cruise Passengers from Different Demographic Groups: A Case of China 


\title{
Comparing Motivations and Intentions of Potential Cruise Passengers from Different Demographic Groups: A Case of China
}

\begin{abstract}
The cruise industry is the fastest growing leisure market in the world. As an essential component, the cruise market in China is growing rapidly over the recent years with the introduction of favorable government policies, new cruise terminals, and increased cruise awareness of customers. Unfortunately, only few studies have investigated the perceptions of Mainland Chinese consumers toward such industry. Hence, by adopting qualitative and quantitative research methods, this study explored how the motivation and intention of potential cruise consumers differed in terms of their demographic background. Travelers from different age, income, and marital status groups demonstrated varying cruise motivations and intentions. The influences of motivation factors on the cruise intention of consumers were also explored. Both the theoretical and practical contributions of the study were put forward accordingly.
\end{abstract}

\section{Keywords}

Cruise, demographic background, motivation, intention, China

\section{Introduction}

The current tourism market trend indicates that consumers are more diversified than ever before. Empirically, profiling travel segments allows travel operators to improve the designing and promotion of their travel products. As an essential segmentation instrument, the demographic segment can precisely define the trends and preferences of people from groups with varying demographic information, such as age, gender, marital status, income, and educational level. 
Theoretically, some demographic segments (e.g., the Y Generation) have become very significant, which drove researchers to perform tailor-made studies and formulate models to address the research questions that are related to these segments (Benckendorff, Moscardo, \& Pendergast, 2010; Jang, Kim, \& Bonn, 2011; Nusair, Parsa, \& Cobanoglu, 2011). To date, many studies have investigated the demographic segmentation of consumers, but only few have focused on the motivational and intentional tendency of consumers for each segment. Generating the segmentation of consumers is merely the starting point. Given that the segmentation becomes more meaningful after the characteristics and preferences of each segment are revealed, this study takes the cruise market in Mainland China as an example to explore how the motivation and intention of cruise consumers differ in terms of their demographic background. This paper also aims to verify the effect of cruise motivation on future cruise intention.

The cruise industry continues to flourish over the years. From 1980 to 2013, more than 246 million travelers have taken a deep water cruise, and the global passenger forecast in 2014 is 21.7 million guests (Florida Caribbean Cruise Association, 2014). Among all kinds of travels in the entire leisure market, cruising has become one of the fastest growing categories with an average annual passenger growth rate of 7.2\% per annum (Florida Caribbean Cruise Association, 2014).

Although the capacity share of cruising in Asia is 3.6\%, this market has been estimated to have generated the highest capacity growth of 302\% from 2008 to 2013 (Cruise Lines International Association, 2013). Several cruise operators have gradually begun their operations in Asia, especially in China. Costa Victoria introduced short cruises from Hong Kong, Shanghai, and Tianjin to Taiwan or South Korea, Japan, and Vietnam. Azamara Club Cruises has featured 40 new ports, including Beijing (Xingang in Tianjin), Shanghai, and Jinhae, South Korea in the 
Far East. More homeports in Asia are now capable of serving large, luxury ships. The specialty port of Shanghai received 62 international lines in 2012. In 2013, the number was expected to increase to more than 217 and in 2015, the number is expected to increase to 300 (China Market Report Center, 2014). According to the survey by the Cruise Lines International Association (2013), ethnic groups, wedding attendants, and honeymooners represent the top three growth potential target groups. Many researchers believe that the number of Asian cruise travelers will increase because more than 85 million Chinese are capable of taking international vacations (Josiam, Huang, Spears, Kennon, \& Bahulkar, 2009). On August 15, 2013, the China National Tourism Administration published a detailed memorandum for Mainland cruise travelers regarding the cruise itinerary from Hong Kong to Japan and South Korea via Taiwan. Several cruise harbors have been established in Shanghai, Xiamen, Sanya, and Tianjin. The Chinese Government has regarded the cruise industry as a main economic growth pillar in the next five years (Anonymous, 2010).

Cruising is a new concept in contemporary China because of the limited development and the restrictions that have been previously implemented on outbound tourism. However, the market demonstrates a great potential, which highlights its role as an essential component of the Asian market. China has a relatively small yet fast-growing stratum of middle class people who will become interested in cruising when they consider such conspicuous consumption a status symbol (Wei, 2004). Given this opportunity, the motivation and intention of Chinese consumers to go cruising must be explored to understand further the potential of the Chinese cruise market.

Many scholars have examined the North American and European cruise markets, but only few researchers have focused on the Asian cruise market, especially that of China, which has a huge potential to become a major player in the global cruise market. Although several studies 
have explored both the Hong Kong and Taiwan cruise markets (Qu \& Ping, 1999; Josiam et al., 2009), only a few have investigated the emerging cruise market in Mainland China (Fu, Huang, \& Cai, 2010). Moreover, most of the extant demographic studies have emphasized the demographic allocation of existing consumers, whereas only few studies have investigated the motivational traits and intentional attitudes of potential consumers. The diverse travel motivations and intentions of people from different demographic segments are also relatively unexplored. Given that the international cruise tourism in Mainland China is still in its infancy, most residents in Mainland China, especially those from remote regions, have limited access to the latest information on cruise travel. However, this fact reveals the potential of Mainland China to become a major cruise market in the future. Understanding the psychological and behavioral characteristics of the Mainland Chinese population is essential for cruise operators and marketers. Consequently, this study bridges the aforementioned gaps by exploring the motivations and intentions of potential Mainland China cruise travelers from different demographic groups. Specifically, this research intends to achieve the following objectives:

1. To assess how the motivation and intention of potential cruise consumers differ in terms of their demographic background;

2. To estimate the effect of cruise travel motivation on future intention; and

3. To provide tailor-made marketing implications for cruise practitioners.

\section{Literature Review}

To understand the research context and to build a sound theoretical groundwork, this section summarizes the extant literature on each key concept in this study. Specifically, the previous studies on demographics, motivation, and intention are reviewed. The correlation 
between travel motivation and travel intention are discussed. Research gaps are determined from the review and discussion.

\section{Demographics}

Demographic attributes refer to several indicators, such as age, gender, marital status, educational level, occupation, and income level (Mak, Lumbers, Eves, \& Chang, 2012). Many studies have explored the demographic differences in various research fields, such as attitude (Lee \& Hwang, 2011), motivation (Zhang \& Lam, 1999), food preference (Mak et al., 2012), online channel selection (Qi, Law, \& Buhalis, 2013), transportation selection (Le-Klähn, Gerike, \& Hall, 2014), and destination image (Beerli \& Martín, 2004).

In their pioneering study on the differences of demography on travel motivation, Zhang and Lam (1999) found significant differences in the push and pull motivation factors for people with varying income, age, gender, and travel frequency. In terms of destination image, the affective and cognitive components of destination image are significantly different across the socio-demographic factors of tourists, such as gender, age, education level, and social class (Beerli \& Martín, 2004). In the food and beverage field, demographic attributes differentiate the attitudes of consumers toward luxury restaurants. For instance, low-income individuals express more unfavorable attitudes toward luxury restaurants than middle- and high-income populations. However, gender and age are insignificant (Lee \& Hwang, 2011). Several studies (Khan, 1981; Rozin, 2006; Tse \& Crotts, 2005) also claimed that the preferences of tourists in food consumption are different by socio-demographic factors, such as age, gender, and social status. For example, gender, education, income, and region differ the hotel booking and information searching channels of consumers. 
Although several demographic analyses have been performed on the cruise industry, most explored the demographic distribution of existing passengers rather than the motivational and intentional differences across demographic groups. Based on interviews with U.S. residents, the Cruise Lines International Association (2011) revealed that most cruisers are old (with an average age of 48 years and $20 \%$ were retired), with a high education (76\% were college graduates), and with a high income level (with an average household income of USD 97,000). The consumers in the cruise markets of Hong Kong and Taiwan are middle-aged or old with a high consumption power (Qu \& Ping, 1999; Josiam et al., 2009). Specifically, a study of Taiwanese cruisers (Josiam et al., 2009) revealed that satisfaction level is differentiated by gender and first time visit or repeat visit. Given the immaturity of such market, limited information on the Mainland Chinese cruise market can be found. One report from Royal Caribbean International (2013) stated that the cruise passengers from Mainland China are mostly young, highly educated, and middle class customers (Sun, Feng, \& Gauri, 2014). The cruise market in Mainland China is at an early stage of development. Therefore, only few studies have explored the demographic attributes in this market and on the psychological and behavioral tendencies of potential cruise passengers. This study aims to examine if the cruise motivation and intention of potential cruise passengers vary among demographic variables.

\section{Motivation}

Understanding consumer motivations, destination choices, service quality, and satisfaction can help marketers predict future travel patterns and achieve successful tourism marketing (Dann, 1981). The motivation of cruisers must be investigated to understand their traveling behavior; motivation also has a significant role in examining the travel decision-making 
process and assessing the satisfaction of tourists (Snepenger, King, Marshall, \& Uysal, 2006).

Motivation refers to the state of need or a condition that propels an individual to perform a certain action that elicits satisfaction (Moutinho, 2000). Motivation factors are psychological needs that have significant roles in causing a person to feel a psychological imbalance that may be corrected through a travel experience (Crompton, 1979; Kim, Crompton, \& Botha, 2000). People may intend to go on a trip to fulfill their biological (food, climate, and health) and psychological (adventure and relaxation) needs (Mayo \& Jarvis, 1981). Proposed by Iso-Ahola (1982), seeking-escaping tourism theory argues that individuals participate in leisure activities to derive satisfaction by seeking (intrinsic rewards) or escaping (from routine/familiar environments).

Previous studies argued that push and pull motivations have been primarily utilized in the realm of tourist behavior (Yoon \& Uysal, 2005). Push motivations are connected to the desire of tourists, whereas pull motivations are related to the attributes of the destination choices (Crompton, 1979; Dann, 1981). Crompton (1979) drew seven socio-psychological (push) motivations (i.e., escape, self-exploration, relaxation, prestige, regression, kinship-enhancement, and social interaction) and two cultural (pull) motivations (novelty and education). Push motivations are related to internal or emotional aspects, whereas pull motivations are related to external, situational, or cognitive aspects (Yoon \& Uysal, 2005).

Push and pull motivations have been broadly applied to various segments in the tourism market. For instance, six push and three pull motivation factors of second-home owners in relation to the purchase of nature-based tourism activity products have been identified (Tangeland, Vennesland, \& Nybakk, 2013). Leong, Yeh, Hsiao, and Huan (2015) explored the interaction between push and pull motivations. They found that nostalgia push motivation 
positively affects two pull motivations, namely, historical and heritage attraction as well as family and friend bonding opportunities. Some studies unveiled the push and pull motivations in the Greater China market. For instance, the push and pull motivations of Chinese outbound tourists were investigated (Hsu, Cai, \& Li, 2010; Zhang \& Peng, 2014). It was argued that the pull motivation factors for Mainland tourists traveling to Cairns, Australia were "various activities for fun”, “relaxing environment” and "easy accessibility”. The push factors included "personal relationships", "fun and self-satisfaction” and "relaxation and knowledge” (Zhang \& Peng, 2014). Taking Mainland Chinese tourists to Hong Kong as example, Hsu et al. (2010) stated that, "knowledge”, "relaxation" and "novelty” were their pull motivations and "shopping” was their push motivation. Some scholars (Jang \& Wu, 2006; Hsu, Cai, \& Wong, 2007; Jang, Bai, $\mathrm{Hu}, \& \mathrm{Wu}, 2009)$ also examined the motivations of travelers in the senior travel markets of Mainland China and Taiwan, which included "ego-enhancement”, "self-esteem", "knowledge/novelty-seeking”, “relaxation” and "socialization” as push factors and "cleanliness \& safety", "facilities, event, \& cost” and "natural \& historical sight” as pull factors.

\section{Cruising Motivation Factors of Cruise Travelers by Region}

Motivation is dynamic; thus, such concept may differ from one individual to another, from one destination to another, from one market segment to another, and from one decisionmaking process to the next (Uysal \& Hagan, 1993; Witt \& Wright, 1992). Given this perspective, the motivations in various countries, markets, segments, and destinations must be identified.

Few studies have explored the push and pull motivation factors of travelers from different cruise markets. Hung and Petrick (2011) developed a scale for measuring the motivations of consumers in the North American cruise market, including their "self-esteem and social 
recognition,” “escape/relaxation,” "learning/discovery and thrill,” and “bonding.” The motivations of white Caucasians and ethnic minority passengers to go on a cruise were also compared (Teye \& Leclerc, 2003). The motivation factors for white Caucasians include "social dimension”, “cultural discovery”, “family/kinship attributes”, “national/physical considerations”, “escape from social pressures”, “mental/personal considerations”, “uninhibited pursuits”, and “special treatment”. By contrast, the motivation factors for ethnic minority include uninhibited pursuits, cultural discovery, entertainment opportunities, personal considerations, family/kinship attributes, natural physical considerations, and personal renewal. In other words, although a set of common factors motivate both white Caucasians and ethnic minorities, several important differences exist between these groups.

Lu (2001) identified five push and five pull motivation factors for Taiwanese cruise travelers. Push factors include “lifelong learning,” “escape and relaxation,” “adventure,” “belonging,” and "status seeking,” whereas pull factors include "national environment and safety," “entertainment and sports recreation,” “nature and wilderness," "learning opportunity,” and "modernity and facilities.” Another study of Taiwanese cruise travelers (Josiam et al., 2009) identified “discovery,” “enjoyment,” “social esteem,” “need,” “escape,” and “family time” as the core motivating push factors, whereas the pull motivation factors were defined as unifactorial.

Qu and Ping (1999) identified “escape from normal life,” "social gathering,” and "beautiful environment and scenery" as the major travel motivation factors in the Hong Kong cruise market. Fu et al. (2010) studied the motivations of Chinese cruise tourists from a cultural historical perspective and proposed a theoretical model of such motivation. How the Chinese associate the characteristics of water, including life, flow, energy, purity, freshness, and natural state of being, with their leisure travels affect their motivation. The push factors for Chinese 
cruise tourists include "spiritual purification,” "moral enlightenment," “relaxation and refreshment,” “escaping,” “social gathering,” “family happiness,” and “cultural discovery,” while the pull factors include “openness,” “freedom,” "beautiful scenery,” “cultural attributes,” and “entertainment.” However, this proposed model needs to be empirically tested in the context of the Chinese cruise market.

\section{Intention}

Intention refers to the planned or anticipated future behavior of an individual (Swan, 1981). This concept also represents the expectations of an individual about a particular behavior in a specific situation and can be operationalized as the likelihood to act (Fishbein \& Ajzen, 1975).

In the cruise industry, Petrick (2004) identified quality and perceived value as the antecedents of satisfaction that could eventually lead to the behavioral intention of cruise passengers. Petrick (2005) found that visitors with higher price sensitivity have a higher intention to repurchase cruise products, which reflects that less price-sensitive visitors are more likely to spend more, whereas more price-sensitive visitors are more likely to evaluate their experiences positively. Critical incidents (Petrick, Tonner, \& Quinn, 2006) and perceived image of cruise travel (Park, 2006) also influence the behavioral intention of cruise passengers.

\section{Motivation and Intention}

Motivation is a critical element in determining the travel behavior of individuals. Many studies have shown that travel motivation affects the intention of an individual to revisit a 
destination or repurchase a travel product. Ajzen (1991) also supported the relationship between motivation and intention in which intention comprises motivational factors that could influence behavior. However, although the relationship between motivation and intention is generally accepted, the relationship between the motivational factors and intention must also be examined because the former relationship is only applicable to certain motivational attributes ( $\mathrm{Li}$, Cai, Lehto, \& Huang, 2010).

Intention and motivation are closely correlated and have important roles in the destination selection of travelers. Among the motivation scales for American cruise travelers, Hung and Petrick (2011) found that "escape/relaxation” has the most significant contribution to cruise intention, followed by "learning/discovery and thrill," "self-esteem/social recognition," and "bonding." The influence of all four motivation factors on cruise intentions indicates a positive relationship between the two variables, which implies that after controlling for other conditions, people who have a higher cruising motivation are more likely to go on a cruise in the future.

Although the relationship between motivation and intention has been studied to some extent, such relationship in the Chinese cruise market must also be investigated. Gorham and Rice (2007) argued that a cruise is not a one-size-fit-all type of product and that the motivation and intention toward cruise travel that has been reported in western countries might not be the same as those in Mainland China. Previous studies have shown that several variables, such as the perceptions of tourists toward a destination or a hospitality establishment, their satisfaction levels, demographic profiles, and tourism activities may vary according to their countries of origin (Kozak, 2002). For example, Singh (1999) suggested that Asians generally lack awareness about the cruise market. Some Asian consumers still perceive ships merely as a mode of transportation. Asian consumers also perceive cruises as exclusive products for affluent people (Josiam et al., 
2009). Based on this perception, the relationship between motivation and intention must be studied in the context of Mainland China, where the cruise industry is not as well-developed compared with that of western countries. Furthermore, the existing studies on the relationship between motivation and intention in the cruise market have mainly focused on the revisiting intention of cruise travelers. By contrast, this study focuses on potential cruisers. Targeting at the potential Chinese cruisers is determined by the reality of the Chinese cruise market. In 2011, Chinese cruise tourists was approximate 700,000 (Sun et al., 2014). Considering within the entire population of 1.36 billion, the majority of Mainland Chinese residents do not have cruise experience. Facing the reality of the immature but emerging market, it is more practical to explore potential cruisers' motivation and intention rather than experienced cruisers' revisit motivation and intention. Meanwhile, understanding the motivation and intention of this potential market may better facilitate cruise practitioners to arouse potential customers' interest to cruise and also to acquire psychological basis for the product design, marketing and promotion.

\section{Methodology}

Both qualitative and quantitative research methods were applied in this study. Previous literature provided a basis for measuring the constructs of motivation and intention. However, due to the differences in tourism segments and research contexts, motivation items from mass tourism markets and/or those developed from other cultural contexts may not precisely represent the cruise motivations for Chinese customers. To generate a comprehensive and appropriate measurement instrument for the potential cruise travelers in Mainland China, a focus group interview was conducted to verify the existing measurement items, to obtain additional insights, and to explore additional measurement items on cruise motivation and intention during the 
development of the survey instrument. The derived results were applied in the second part of the questionnaire. The focus group consisted of five Mainland Chinese, of which one was male and four were females, with ages from 25 years to 42 years. In terms of occupation, two interviewees worked in the hospitality industry, one worked as a travel agent, one taught in a local college, and one was employed in a consulting company. All interviewees went on a cruise before. They were asked to discuss about their own experiences, share some new attributes, and evaluate the existing attributes from literature according to their perceptions. Twenty four motivation attributes and five intention attributes were obtained from both the literature and focus group interviews. Specifically, with regard to the motivation attributes, "Enjoy spa" was obtained from the focus group interview and all other attributes were obtained from previous literature (Josiam et al., 2009; Hung \& Petrick, 2011; Qu \& Ping, 1999; Hsu et al., 2010; Fu et al., 2010). In terms of the intention items, "I am interested in cruise travel" was generated from the focus group interviews, while the remaining items were adopted from previous literature (Lam \& Hsu, 2006; Hung \& Petrick, 2011). For the quantitative research, a questionnaire was designed to collect the primary data. The questionnaire comprised two sets of questions. The first set presented six demographic questions to obtain the background information of the respondents. Gender, age, educational level and income level were adopted from the aforementioned demographic studies (e.g. Zhang \& Lam, 1999; Beerli \& Martín, 2004; Lee \& Hwang, 2011). Marital status and family size were adopted from Qu and Ping’s (1999) study which examined Hong Kong cruisers’ profile, motivation and satisfaction. The second part included 24 motivation attributes and five intention attributes that were derived from both the literature review and the focus group interview. A seven-point Likert-type agreement scale was adopted for these questions: $1=$ Strongly Disagree, $2=$ Disagree, $3=$ Somewhat Disagree, $4=$ Neither Agree nor Disagree, $5=$ 
Somewhat Agree, 6= Agree and $7=$ Strongly Agree. For the motivation statements, the respondents were asked to indicate the extent to which the statements stimulated their desire to go on a cruise. For the intention statements, the respondents were asked to specify the extent to which the statements represented their intention to go on a cruise in the future.

The questionnaire was originally designed in English. To facilitate distribution, the questionnaire was translated into simplified Chinese. The back translation approach was adopted. After being translated from English into simplified Chinese by a tourism researcher, the simplified Chinese version was translated into English by another researcher. After the back translation, both versions of the questionnaires were modified to ensure that the intention of the statements was precisely stated. The modified questionnaire was also reviewed by two tourism researchers (one senior and one junior) with competencies in both languages to ensure the accuracy of translation.

The potential outbound cruise travelers in China were targeted for the survey. A pilot study was conducted among 20 Mainland Chinese students who studied in a hotel and tourism management school in Hong Kong to test the feasibility of the questionnaire. Twenty master's degree students from Mainland China were asked to answer the questionnaire in simplified Chinese. The suggestions of the respondents were solicited during the pilot test and several problems were identified. First, the questions were written in small font, which was inconvenient for the senior respondents. Second, some scale items needed to be clarified further to avoid polysemy. Third, the back page was ignored by three out of the 20 respondents. Therefore, the passage "Questions continue at the back" was added at the bottom of the first page to remind the participants to turn the page. After the pilot study, the questionnaires were distributed to potential cruise travelers at universities, parks, coffee shops, restaurant waiting areas, and company offices 
in Beijing and Shanghai. Mainland Chinese residents who never experienced an outbound cruise were the target respondents for this study. Before distributing the questionnaires, a screening question "Have you ever been to an outbound cruise travel before?” was asked to determine the appropriate respondents. If the individuals answered "no," they were requested to answer the survey. Otherwise, the survey was terminated. After explaining the purpose of the study, the participants were asked to answer the questionnaire on site. A total of 250 questionnaires were distributed, of which 242 were valid. Thus, a 96.8\% response rate was achieved. All respondents had never taken an outbound cruise before, but two respondents previously went on a domestic cruise.

\section{Findings}

The demographic profiles of the respondents were examined to provide some background information (Table 1). The female respondents (54.7\%) outnumbered the male respondents (45.3\%). Over half of the respondents were aged 25 years or below, 32.8\% were aged between 26 years and 35 years, $7.3 \%$ were aged between 36 years and 45 years, and $4.7 \%$ were aged between 46 years and 65 years. In terms of marital status, $72.8 \%$ of the respondents were single, 18.5\% were married with child(ren), and $8.6 \%$ were married, but without child(ren). In terms of family size, most respondents had a three-person family (43.5\%). The majority of the respondents had a college diploma or a university degree (64.1\%), followed by postgraduate or above (33.2\%). Most respondents (76.9\%) had an annual household income of less than RMB 150,000, and approximately $10 \%$ of the respondents had an annual household income of higher than RMB 300,000. The age and educational status of the sample are generally in line with previous statistics, which emphasizes that, unlike other markets, the cruise market in Mainland 
China is not exclusive to elderly customers as shown in the case of Europe (Mondou \& Taunay, 2012). This finding may be attributed to the general perception of young travelers that cruises are romantic undertakings. Sun et al. (2014) showed that the Chinese market is young and highly educated, which indicates that the majority of the Chinese cruise travelers belong to the new generation. Some demographic groups had a relatively small percentage, which may be too specific to generate any convincing conclusion. Therefore, age group, marital status, and total household annual income were partially combined.

\section{Insert Table 1 Here}

Descriptive statistics was used to obtain the mean value of each item under motivation (Table 2) and intention (Table 3). The highest mean score of motivation was obtained by "Enjoy beautiful environment and sceneries" $(M=6.36)$, followed by "See attractive routes and destinations" ( $M=5.99)$, "See and experience a new culture" $(M=5.98)$, "Visit different places in one trip" $(M=5.86)$, and "Travel to places that friends/relatives have never visited" $(M=$ 5.73). "Enjoy casino experience" ( $M=2.81)$ obtained the lowest mean score of motivation, which might be explained by the fact that gambling in public strictly is prohibited in Mainland China. Gambling is also perceived by the Chinese society as a negative activity (Hsieh, 2002). Therefore, to create a socially desirable presentation of self, the respondents may have distorted their responses by giving a lower rating to "Enjoy casino experience” (Wood \& Williams, 2007). For intention to cruise, "I am interested in cruise travel" received the highest rating ( $M=5.47)$, while "I intend to go on a cruise in the next three years" obtained the lowest rating ( $M=4.53)$. It should be remarked that intention items of "I'll recommend cruise to others" and "I'll encourage friends and relatives to go on cruise” should be interpreted with caution. Potential cruisers rate those two items according to their limited awareness and understanding of cruise travel rather 
than their own cruise experience.

\section{Insert Table 2 and 3 Here}

Principal component factor analyses with varimax rotation were conducted to group the motivation items with similar measurement characteristics. In the first-round analysis, the item “Experience a new form of transportation” was discarded because of the low factor loading. In the second-round analysis, the item "Enjoy different cuisines and beverages” was removed as the cross-loading occurred. Table 4 shows that 22 items were selected and grouped into five factors and explained $61.60 \%$ of the variance. All variables had a factor loading higher than 0.5. All factors had an eigenvalue higher than 1 and a Cronbach's alpha of 0.7 and above. These factors were labeled as Relaxation and Family, Discovery, Enjoyment, Wellness and Socialization, and Social/Esteem Need. Based on the definition of push and pull motivations (Crompton, 1979; Dann, 1981), the five motivation factors were divided into three pull factors (Discovery, Enjoyment, and Wellness and Socialization) and two push factors (Relaxation and Family and Social/ Esteem Need). The result also unveiled that, unlike the motivation factors identified in Taiwan cruise market (Josiam et al., 2009), “Experience a new form of transportation” and "Enjoy different cuisines and beverages" did not significantly contribute to the factors of Discovery and Enjoyment respectively in the current study.

\section{Insert Table 4 Here}

T-tests and ANOVA were applied to identify the differences in the motivation and intention of various demographic groups. With regard to the motivation factors, people from different age, income level, and marital status groups demonstrated varying degrees of motivation. However, gender, family size, and educational level had no significant effect on cruise motivation and intention. Specifically, the ANOVA results showed significant differences 
in the motivation factors of the respondents from different age groups (Table 5). The respondents in age group "26 years to 35 years" had a significantly lower mean than those in " 25 years or below" and "36 years or above" age groups for both Enjoyment $(\mathrm{F}=5.9, \mathrm{P}<0.01)$ and Wellness and Socialization $(\mathrm{F}=6.7, \mathrm{P}<0.01)$.

In terms of total household annual income (Table 6), the respondents with an annual income level of "RMB 250,000 or above" had a significantly higher mean for Relaxation and Family than those respondents with lower income $(\mathrm{F}=3.2, \mathrm{P}<0.05)$. In terms of marital status (Table 7), the single respondents had a significantly higher mean for Discovery than the married ones $(\mathrm{T}$-value $=2.0, \mathrm{P}=0.05)$. The respondents from different age and income groups also demonstrated differences in their cruise intention (Tables 5 and 6). The respondents in the age group "36 years or above" had a significantly higher intention to cruise in the next three years than those in the age group of "25 years or below" $(\mathrm{F}=2.8, \mathrm{P}<0.07)$. Similarly, the respondents with an annual income level of "RMB 250,000 or above" had a higher intention to cruise in the near future than those with an annual income of "below RMB 50,000" $(\mathrm{F}=2.8, \mathrm{P}<0.05)$.

\section{Insert Table 5-7 Here}

Multiple linear regression was performed using SPSS to test the relationship between motivation and intention. Relaxation and Family $($ Beta $=0.211, \mathrm{P} \leq 0.01)$ and Enjoyment $($ Beta $=$ $0.301, \mathrm{P} \leq 0.001)$ significantly and positively affected cruise intention $(\mathrm{F}=17.601, \mathrm{P}<0.001$, adjusted $\mathrm{R}^{2}=0.267$ ) as shown in Table 10 . The other three factors were insignificant.

\section{Insert Table 8 Here}

\section{Discussion and Implication}


By using the cruise market in Mainland China as a research background, this study explored how the motivation and intention of cruise consumers differed in terms of their demographic background. The effect of cruise motivation on future cruise intention was also verified.

The motivations of respondents from different age, income level, and marital status groups were significantly different from one another. The respondents in the "26 years to 35 years” age group had a significantly lower mean for Enjoyment and Wellness and Socialization than those in the " 25 years or below" and "36 years or above" age groups. This result was unsurprising as people in such age group are often in the stage of starting their careers and families, which brings additional pressure. The health condition of people at this age range is normally not a serious issue. Consequently, these people might not show considerable concern for the above motivation factors. In contrast, those people above 36 years who reported a significantly higher mean for Enjoyment were more mature and stable in their careers, finance, and family status. Enjoying life and maintaining favorable health are more important for these people. With regard to marital status, single people had a significantly higher mean for Discovery than those who were married, which indicates that singles are actively motivated by the discovery and exploration natures of cruises. Compared with married people, single individuals have more freedom to try new and exciting things without much concern on the preferences and capacity of their families.

In terms of income level and motivation, the respondents with an annual income level of "RMB 250,000 or above" had a significantly higher mean for Relaxation and Family than those with a lower income. It is consistent with the general perception that cruise travel is perceived as a luxury experience compared with other ways of travel because of the high expenses and 
pampered arrangement that are associated with such travels. Many working people with higher financial ability sacrifice their leisure and family time for a better compensation. These people may try to compensate for their lost time with their families whenever possible. Therefore, the higher income group is more motivated by Relaxation and Family than the lower income group. Income level also had a significant effect on intention. This finding is consistent with that of the Cruise Lines International Association (2011), which revealed that the median age of cruisers is 48 years and $20 \%$ of these cruisers are retired. As reported, the higher income segments comprised a larger share of cruise passengers. Both cruisers and travelers in other leisure markets perceived cruising as more expensive than land-based trips, but had a high value for money. The target market of cruise companies also tended to be more upscale. Similarly, Qu and Ping (1999) studied Hong Kong cruise travelers and found that this group usually has the financial ability, energy, and interest to explore the new types of vacations. Among Mainland Chinese, cruise traveling is still considered as an adventurous and luxurious undertaking.

The relationship between motivation and intention was examined and partially supported, which partially confirms the findings of Hung and Petrick (2011). In their study, the factors of “self-esteem and social recognition,” “escape/relaxation,” “learning/discovery and thrill,” and “bonding” could influence cruise intention. The items for Relaxation and Family and Enjoyment employed in this study were similar to the items for "escape/relaxation," "learning/discovery and thrill,” and “bonding.” In contrast, Hung and Petrick (2011) found that the factors of "self-esteem and social recognition” and "learning/discovery and thrill” are insignificant, which suggests that the motivation dimensions of Discovery, Wellness and Socialization as well as of Social/Esteem Need, despite their importance as driving forces, are not critical enough to inspire travel intention. This contrasting result also indicates that conducting similar studies in various cultural 
backgrounds or markets could generate varying results because motivation and intention are both dynamic and strongly affected by consumers per se. Broadly speaking, several studies have already identified that individuals may have various travel motivations toward a travel product, but not all motivations can be antecedents of purchasing intention. For instance, novelty seeking was the only determinant of travel intention examined in the Taiwanese senior travel market (Jang et al., 2009). In the context of Mainland China, shopping dimension is the only significant motivation that drove the intention of Mainland Chinese to travel to Hong Kong (Huang \& Hsu, 2009). In an extreme case, none of the three motivation constructs (intellectual, escape, and belonging) could influence the visit intention of rural tourists in the U.S. (Li et al., 2010). Therefore, although theory of planned behavior implies a relationship between travel motivation and intention, such relationship only takes place through certain motivational dimensions. Practically, when selling cruise products, cruise operators must attract consumers by promoting the Relaxation and Family and Enjoyment constructs, which can directly motivate the consumers to cruise, take a break from their work, enjoy their time with their families, enjoy different kinds of entertainment, shows, and facilities on board, and visit different destinations in one trip.

To profile the Mainland Chinese consumers in the cruise market, mature individuals (aged 36 years or above) with a higher income level (household annual income of RMB 250,000 or above) are highly motivated by enjoyment, wellness, relaxation, and family to go on a cruise, whereas young, single people are highly motivated by discovery. Consumers in the upper-scale income level show a higher intention to purchase cruise products in the near future. These findings can be used by travel agents or cruise lines when designing specific cruise products for Chinese consumers. Practitioners must also hold promotions or campaigns according to the preferences of different consumer segments. For instance, travel agents can promote "Family 
Carnival Tour" to those consumers who want to enjoy their time with their families, promote "Body and Soul Retreatment” with spa, yoga, and Tai Chi activities to consumers who want to pursue a healthy life and spiritual release, and promote "Ocean Adventuring Tour” to young and single travelers. In addition, promoting the awareness of Chinese consumers regarding cruise products can relieve these consumers from their worries and uncertainties about going on a cruise. Given the increasing number of cruise ports in China, going on a cruise becomes more convenient especially to residents of coastal regions. Therefore, promoting such convenience and lowering the barriers to taking a cruise are also crucial to the development of the Chinese cruise market.

\section{Conclusion and Limitations}

This study is one the few pioneering attempts that explore the cruise motivation and intention of Mainland Chinese consumers. Theoretically, this study verified the cruise motivation and intention of potential Mainland Chinese cruise passengers and further examined the cruise motivational and intentional differences among demographic groups. Age, marital status, and income level significantly differentiate cruise motivation and intention, whereas gender, family size, and education are insignificant. Cruise motivation, particularly the factors of Relaxation and Family and Enjoyment, positively affect cruise intention. Being consolidated in the focus group interview and further testified via statistical analyses, the tailor-made measurement scales in this study could be used by future motivation and intention studies in the context of Mainland China. The findings of this study can also be used by cruise lines and tour operators to gain a better understanding of the largest potential cruise market in the world, to design products that address their special needs, and to formulate marketing strategies for attracting more customers. 
Similar to other research, this study has several limitations. As a non-probability sampling method, convenience sampling may result in some problems. For instance, the respondents in this study are relatively young and highly educated and all of them come from Beijing and Shanghai. Therefore, this sample may not represent the entire Mainland China, hence affecting the generalizability of the results. Future research may try to optimize the sample demographics and select samples from diverse geographic regions to avoid any potential bias.

\section{References}

Ajzen, I. (1991). The theory of planned behavior. Organizational Behavior and Human Decision Processes, 50, 179-211.

Anonymous. (2010 November 10). Italian cruise company, Costa Cruises, coming to China. Top Talent, p. 58.

Beerli, A. \& Martín, J. D. (2004). Tourists’ characteristics and the perceived image of tourist destinations: A quantitative analysis-A case study of Lanzarote, Spain. Tourism Management, 25 (5), 623-636.

Benckendorff, P., Moscardo, G. \& Pendergast, D. (2010). Tourism and generation Y. CABI.

China Market Report Center (2014). Wusong international cruise terminal in Shanghai has established two large-scale cruise berths. Retrieved Jan 16, 2015 from http://www.chinairn.com/print/3900314.html

Crompton, J. M. (1979). Motivations for pleasure vacation. Annals of Tourism Research, 6 (4), 408-424.

Cruise Lines International Association, Inc. (2011). 2011 Cruise market profile study. Retrieved Sep 25, 2014 from http://www.cruising.org/sites/default/files/pressroom/Market_Profile 
_2011.pdf

Cruise Lines International Association, Inc. (2013). 2013 North America cruise industry update.

Retrieved Sep 5, 2014 from http://www.cruising.org/sites/default/files/pressroom/

CruiseIndustryUpdate2013FINAL.pdf

Dann, G. M. (1981). Tourism motivations: An appraisal. Annals of Tourism Research, 8 (2), $187-219$.

Fishbein, M. A., \& Ajzen, I. (1975). Belief, attitude, intention and behavior: An introduction to theory and research. Reading, MA: Addison-Wesley.

Florida-Caribbean Cruise Association, Inc. (2013). Cruise industry overview-2013. Retrieved Sep 5, 2014 from http://www.f-cca.com/downloads/2013-cruise-industry-overview.pdf

Florida-Caribbean Cruise Association, Inc. (2014). Cruise industry overview-2014. Retrieved Jan 5, 2015 from http://www.f-cca.com/downloads/2014-Cruise-Industry-Overview-andStatistics.pdf

Fu, X. X., Huang, J., \& Cai, L. A. (2010). Chinese cruise tourists' motivations-A culturalhistorical perspective. In L. Lowry (Ed.), Proceedings of the 2010 Annual International Society of Travel and Tourism Educators (ISTTE) Conference, October 18-22, 2010 on Board Carnival Cruise Line’s Paradise (Vol. 22, pp 40-50). St. Clair Shores, MI: International Society of Travel and Tourism Educators.

Gorham, G., \& Rice, S. (2007). Travel perspectives: A guide to becoming a travel professional. New York: Delmar Thomson Learning.

Hsieh, C. M. (2002). The policy-making analysis of casino gambling in Penghu County, Taiwan. National Dissertations Database of Taiwan, 90NTU02227017. 
Hsu, C. H. C., Cai, L. A. \& Li, M. (2010). Expectation, motivation, and attitude: A tourist behavioral model. Journal of Travel Research, 49 (3), 282-296.

Hsu, C. H. C., Cai, L. A. \& Wong, K. K. (2007). A model of senior tourism motivationsAnecdotes from Beijing and Shanghai. Tourism Management, 28 (5), 1262-1273.

Hung, K. L., \& Petrick, J. F. (2011). Why do you cruise? Exploring the motivations for taking cruise holidays, and the construction of a cruising motivation scale. Tourism Management, 32 (2), 386-393.

Iso-Ahola, S. E. (1982). Toward a social psychological theory of tourism motivation: A rejoinder. Annals of Tourism Research 9 (2), 256-262.

Jang, S. \& Wu, C. (2006). Seniors' travel motivation and the influential factors: An examination of Taiwanese seniors. Tourism Management, 27 (2), 306-316.

Jang, S., Bai, B., Hu, C. \& Wu, C. (2009). Affect, travel motivation, and travel intention: A senior market. Journal of Hospitality \& Tourism Research, 33 (1), 51-73.

Jang, Y. J., Kim, W. G. \& Bonn, M. A. (2011). Generation Y consumers’ selection attributes and behavioral intentions concerning green restaurants. International Journal of Hospitality Management, 30 (4), 803-811.

Josiam, B. M., Huang, T. Y., Spears, D. L., Kennon, L., \& Bahulkar, G.A. (2009). Understanding ethnic Chinese travelers on North American cruise tours: Motivations, perceptions, and satisfaction of cruisers. Journal of China Tourism Research, 5, 77- 101.

Khan, M.A. (1981). Evaluation of food selection patterns and preferences. CRC Critical Reviews in Food Science and Nutrition 15 (2), 129-153.

Kim, S-S., Crompton, J. L., \& Botha, C. (2000). Responding to competition: A strategy for Sun/Lost City, South Africa. Tourism Management, 21(1), 33-41. 
Kozak, M. (2002). Comparative analysis of tourist motivations by nationality and destinations. Tourism Management, 23, 221- 232.

Lam, T. \& Hsu, C. H. C. (2006). Predicting behavioral intention of choosing a travel destination. Tourism Management, 27 (4), 589- 599.

Lee, J. H. \& Hwang, J. (2011). Luxury marketing: The influences of psychological and demographic characteristics on attitudes toward luxury restaurants. International Journal of Hospitality Management, 30 (3), 658-669.

Leong, A. M., Yeh, S. S., Hsiao, Y. C. \& Huan, T. C. (2015). Nostalgia as travel motivation and its impact on tourists' loyalty. Journal of Business Research, 68 (1), 81-86.

Le-Klähn, D.T., Gerike, R. \& Hall, C. M. (2014). Visitor users vs. non-users of public transport: The case of Munich, Germany. Journal of Destination Marketing \& Management, http://dx.doi.org/10.1016/j.jdmm.2013.12.005i

Li, M., Cai, L. A. \& Lehto, X. Y. (2010). A missing link in understanding revisit intention-The role of motivation and image. Journal of Travel \& Tourism Marketing, 27, 335-348.

$\mathrm{Lu}, \mathrm{C}$. (2001). The study of tourism motivation and experience of the cruise-ship tours-A case study of the Berlitz evaluated 4-star cruise-ships. Master thesis, Taiwan, Chinese Culture University. Retrieved Sep 5, 2014 from http://etds.ncl.edu.tw/theabs/site/sh/detail_result.jsp

Mak, A. H. N., Lumbers, M., Eves, A. \& Chang, R. C. Y. (2012). Factors influencing tourist food consumption. International Journal of Hospitality Management, 31 (3), 928-936.

Mayo, E. J., \& Jarvis, L. P. (1981). The psychology of leisure travel: Effective marketing and selling of travel services. Boston: CBI Publishing Company.

Moutinho, L. (2000). Strategic management in tourism. New York: CABI Publishing. 
Nusair, K., Parsa, H. G. \& Cobanoglu, C. (2011). Building a model of commitment for generation Y: An empirical study on e-travel retailers. Tourism Management, 32 (4), 833843.

Park, S. Y. (2006). Tapping the invisible cruise market: The case of the cruise industry. Unpublished Doctoral dissertation, Texas A\&M University, College Station.

Petrick, J. F. (2004). The roles of quality, value, and satisfaction in predicting cruise passengers’ behavioral intentions. Journal of Travel Research, 42, 397-407.

Petrick, J. F. (2005). Segmenting cruise passengers with price sensitivity. Tourism Management, 26, 753-762.

Petrick, J. F., Tonner, C., \& Quinn, C. (2006). The utilization of critical incident technique to examine cruise passengers’ repurchase intentions. Journal of Travel Research, 44, 273280.

Qi, S., Law, R. \& Buhalis, D. (2013). Who booked five-star hotels in Macau? A study of hotel guests' online booking intention. Journal of Hospitality \& Tourism Management, 20, 7683.

Qu, H. L., \& Ping, E. W. (1999). A service performance model of Hong Kong cruise travelers' motivation factors and satisfaction. Tourism Management, 20, 237- 244.

Royal Caribbean International (2013). The Chinese cruise market profile study. Presented in the 8th China Cruise Shipping \& International Cruise Expo, Shanghai, China, 15-17 November 2013.

Rozin, P. (2006). The integration of biological, social, cultural and psychological influences on food choice. In: Shepherd, R., Raats, M. (Eds.), The Psychology of Food Choice. CAB International, Oxfordshire, pp. 19-39. 
Singh, A. (1999). Growth and development of the cruise line industry in Southeast Asia. Asia Pacific Journal of Tourism Research, 3 (2), 24- 31.

Snepenger, D., King, J., Marshall, E. \& Uysal, M. (2006). Modeling Iso-Ahola’s motivation theory in the tourism context. Journal of Travel Research, 45 (140), 12- 30.

Sun, X. D., Feng, X. G. \& Gauri, D. K. (2014). The cruise industry in China: Efforts, progress and challenges. International Journal of Hospitality Management, 42, 71-84.

Swan, J. (1981). Disconfirmation of expectations and satisfaction with a retail service. Journal of Retailing, 57 (3), 49-66.

Tangeland, T., Vennesland, B. \& Nybakk, E. (2013). Second-home owners' intention to purchase nature-based tourism activity products-A Norwegian case study. Tourism Management, 36, 364-376.

Teye, V., \& Leclerc, D. (2003). The white Caucasian and ethnic minority cruise markets: Some motivational perspectives. Journal of Vacation Marketing, 9 (3), 227-242.

Tse, P. \& Crotts, J.C. (2005). Antecedents of novelty seeking: International visitors’ propensity to experiment across Hong Kong‘s culinary traditions. Tourism Management 26 (6), 965968.

Uysal, M., \& Hagan, L. R. (1993). Motivation of pleasure to travel and tourism. In M. A. Khan, M. D. Olsen, \& T. Var (Eds.), VNR'S encyclopedia of hospitality and tourism (pp. 798810). New York: Van Nostrand Reinhold.

Wei, X. A. (2004, July 5). China's cruise liner market is small but hopeful. SinoCast China Business Daily News, p.1.

Witt, C. A., \& Wright, P. (1992). Tourist motivation: Life after Maslow. In P. Johnson, and Thomas (Eds.). Choice and demand in tourism, 33-56. London: Mansell. 
Wood, R. T., \& Williams, R. J. (2007). Internet gambling: Past, present and future. In G. Smith, D. Hodgins, R. J. Williams (Eds.) Research and measurement issues in gambling studies (pp. 491-514). San Diego, CA: Elsevier Publishing.

Yoon, Y., \& Uysal, M. (2005). An examination of the effects of motivation and satisfaction on destination loyalty: A structural model. Tourism Management, 26, 45-56.

Zhang, Q. H., \& Lam, T. (1999). An analysis of Mainland Chinese visitors' motivations to visit Hong Kong. Tourism Management, 20 (5), 587-594.

Zhang, Y. \& Peng, Y. (2014). Understanding travel motivations of Chinese tourists visiting Cairns, Australia. Journal of Hospitality \& Tourism Management, 21, 44-53. 